\title{
UPAYA PENGURANGAN RISIKO BENCANA BANJIR DI MADRASAH TSANAWIYAH MUHAMMADIYAH TRUCUK KABUPATEN KLATEN
}

\author{
Diana Pramesti Listiaji1), Mutiara IImi 2), Sri Wisudaryono3), Dadang Surya Bima ${ }^{4)}$ \\ dan Aprilia Nur Rahmawati ${ }^{5}$, \\ 1,23,4,5Program Studi Pendidikan Geografi, Fakultas Keguruan dan IImu Pendidikan, \\ Universitas Muhammadiyah Surakarta \\ Inanadidi098@gmail.com, 2Mutiarailmi391@gmail.com,3Sudanata17@gmail.com, \\ 4Dadangsuryabima456@gmail.com, 5Apriliarahma798@gmail.com
}

\begin{abstract}
Abstrak: Madrasah Tsanawiyah Muhammadiyah Trucuk merupakan sekolah yang rawan banjir. Oleh sebab itu penelitian ini bertujuan: 1) Mengetahui tingkat pemahaman warga sekolah tentang bencana banjir, 2) Mengetahui tingkat kesadaran warga sekolah terhadap upaya pengurangan risiko bencana banjir dan 3) Mengetahui tingkat kesiapsiagaan warga sekolah dalam upaya pengurangan risiko bencana banjir. Penelitian ini merupakan jenis penelitian survei dengan pendekatan deskriptif. Data dikumpulkan dengan observasi, wawancara, dan kuisoner. Hasil penelitian ini menunjukkan: 1) tingkat pengetahuan warga sekolah mengenai bencana banjir berada pada kategori tinggi $(75 \%)$, 2) tingkat kesadaran warga sekolah terhadap upaya pengurangan risiko bencana banjir berada pada kategori tinggi (47\%) dan 3) tingkat kesiapsiagaan warga sekolah dalam upaya pengurangan risiko bencana banjir juga berada pada kategori tinggi (70\%). Dengan demikian, jika dilihat dari tiga indikator tersebut maka dapat disimpulkan bahwa upaya pengurangan risiko bencana banjir di Madrasah Tsanawiyah Trucuk Kabupaten Klaten berada pada kategori tinggi.
\end{abstract}

Kata kunci: Bencana Banjir, Kesiapsiagaan, Pengurangan Risiko Bencana

\begin{abstract}
Madrasah Tsanawiyah Muhammadiyah Trucuk is a school prone to flooding. Therefore this study aims: 1) Knowing the level of understanding of school residents about flood disasters, 2) Knowing the level of school community awareness of flood disaster risk reduction efforts and 3) Knowing the level of preparedness of school residents in efforts to reduce the risk of flood disasters. This research is a type of survey research with a descriptive approach. Data collected by observation, interview and questionnaire. The results of this study indicate: 1) the level of school community knowledge about flood disasters is in the high category (75\%), 2) the level of school community awareness of efforts to reduce flood risk is in the high category (47\%) and 3) the level of school community preparedness in the effort to reduce the risk of flood disasters it is also in the high category (70\%). Thus, if seen from the three indicators, it can be concluded that efforts to reduce the risk of flood disasters in Madrasah Tsanawiyah Trucuk, Klaten Regency are in the high category.
\end{abstract}

Keywords: Disaster Risk Reduction, Flood Disaster, Preparedness

\section{PENDAHULUAN}

Bencana alam merupakan salah satu masalah besar yang sering terjadi di Indonesia. Bencana adalah peristiwa atau rangkaian peristiwa yang mengancam dan menganggu kehidupan dan penghidupan masyarakat yang disebabkan baik oleh faktor alam dan/atau non alam maupun faktor manusia sehingga mengakibatkan timbulnya korban jiwa manusia, kerusakan lingkungan, kerugian harta benda, dan dampak psikologis. Bencana alam adalah bencana yang diakibatkan oleh peristiwa atau serangkaian peristiwa yang disebabkan oleh alam antara lain berupa gempa bumi, tsunami, gunung meletus, banjir, kekeringan, angin topan, dan tanah longsor (UU.24 Tahun 2007). 
Indonesia merupakan salah satu negara yang rawan bencana. Tahun 2015, International Strategy for Disaster Reduction 2006-2009, Disaster Reduction Campaign dan UNESCO menetapkan bangsa Indonesia pada urutan ke-7 (tujuh) negara di dunia yang rawan bencana alam. Rencana Aksi Nasional pengurangan risiko bencana 2006-2009 menyebutkan ada 3 (tiga) faktor utama penyebab bencana, antara lain: 1) Bahaya alam dan bahaya karena ulah manusia, 2) Kapasitas yang rendah pada berbagai komponen di tingkat masyarakat, dan 3) Kerentanan yang tinggi dari masyarakat, infrastruktur dan elemen di dalam kota/kawasan yang berisiko bencana. Banyaknya daerah rawan bencana di Indonesia dan pentingnya pengurangan risiko bencana merupakan landasan kuat bagi bangsa Indonesia untuk bersama-sama melakukan upaya peningkatan kesiapsiagaan secara terpadu dan terarah. Indonesia dikenal sebagai negara dengan risiko bencana tingkat tinggi karena berada tepat pada pertemuan tiga lempeng besar yaitu lempeng Pasifik, lempeng Eurasia, dan lempeng IndoAustralia.

Bencana sebagai suatu hal yang menjadi ciri khas dan hampir dialami oleh sebagian besar wilayah di Indonesia. Beberapa faktor fisik alam seperti kondisi geomorfologi, kondisi alam dan cuaca, kondisi geologi, hidrologi dan tanah sangat berpengaruh terhadap adanya bencana di Indonesia. Bencana alam yang ditimbulkan oleh faktor sosial budaya seperti ulah manusianya juga dapat menggangu kelangsungan hidup masyarakat terutama di daerah yang sangat rawan bencana. Masih rendahnya pengetahuan masyarakat tentang kebencanaan dan bahaya dalam suatu bencana dapat ditunjukkan oleh banyaknya pula kejadian bencana di Indonesia. Berbagai kejadian bencana yang di alami sebagian besar wilayah di Indonesia ini maka sangat penting sekali memberikan pengetahuan tentang kebencanaan. Kesiapsiagaan merupakan kegiatan yang menunjukkan respon terhadap bencana. Faktor yang berperan dalam kesiapsiagaan bencana adalah masyarakat dan pihak pengambil keputusan. Masyarakat memiliki pengetahuan (Knowledge), sikap (Atitude), dan perilaku (Behavior) yang dapat digunakan untuk mengukur tingkat kesiapsiagaan. Kesiapsiagaan adalah bagian yang integral dari pembangunan berkelanjutan. Jika pembangunan dilaksanakan dengan baik, upaya kesiapsiagaan terhadap bencana akan lebih ringan tugasnya (Kharisma, 2009 dalam Purnamasari, 2013). Upaya pengurangan risiko bencana dapat dilakukan dengan pendidikan kebencanaan baik secara formal maupun informal.

Pendidikan kebencanaan secara formal dapat dilakukan di sekolah dengan melibatkan peran guru sebagai pembimbing. Namun, tidak setiap guru mengerti dan memahami materi tentang kebencanaan serta bagaimana upaya pengurangan resiko bencana. Maka sangat perlu dilakukan pemberian materi mengenai kebencanaan kepada warga sekolah terutama siswa. Pengetahuan tentang kebencanaan sejak dini dapat memberikan pengaruh besar terhadap perubahan keadaan sebelum maupun sesudah adanya bencana. Pemberian materi tentang kebencanaan terutama pada siswa di sekolah dapat dilakukan dengan berbagai cara selain memasukkan materi tersebut pada setiap mata pelajaran maupun implementasi sekolah siaga bencana melalui ekstrakurikuler di sekolah, sekolah juga perlu melakukan sosialisai berbasis kebencanaan pada siswa.

Edukasi tentang tanggap bencana sangat penting dilakukan pada siswa, karena tidak menutup kemungkinan berbagai kegiatan siswa di sekolah berpotensi terhadap ancaman bencana. Salah satu bencana yang dapat dialami siswa di sekolah ialah bencana banjir. Siswa yang berada di sekolah harus selalu siaga dan tanggap ketika terjadinya bencana banjir, terutama untuk meminimalkan risiko yang akan terjadi akibat bencana banjir. Dalam hal ini sangat diperlukan sekali serangkaian kegiatan yang dapat mengurangi risiko bencana, salah satunya dengan pemberian edukasi tentang kebencanaan. Adapun kegiatan edukasi tersebut bertujuan untuk menambah pengetahuan siswa terhadap bencana banjir, sehingga siswa mengerti apa yang harus dilakukan dan yang tidak dilakukan saat terjadinya bencana banjir. Pengetahuan tanggap bencana tersebut akan lebih dipahami oleh siswa apabila dipraktikkan secara langsung dalam kegiatan ekstrakurikuler. Karena pada dasarnya segala kegiatan yang menyangkut kreativitas dan keaktifan siswa sangat mudah ditangkap oleh memori siswa. Siswa akan benar-benar mengerti tentang pengetahuan kebencanaan dan tanggap bencana. Pada akhirnya dengan berbagai pengetahuan tentang tanggap bencana yang dimiliki oleh siswa maka siswa dapat 
menyalurkan pengetahuan tersebut terhadap orang di sekelilingnya. Masyarakat sekitar juga akan semakin paham tentang tanggap bencana sehingga secara bersama-sama dapat melakukan upaya pengurangan resiko bencana dengan memanfaatkan pengetahuan yang dimiliki tersebut yang berwujud dengan kegiatan tanggap bencana maupun mengikuti serangkaian manajemen bencana secara baik dan tepat.

Terdapat beberapa penelitian terdahulu yang mengkaji tentang kesiapsiagaan terhadap bencana banjir. Makassar (2011) misalnya melakukan penelitian dengan fokus kajian pada upaya mengetahui pengaruh penyuluhan kesiapsiagaan terhadap pengetahuan dan sikap kepala keluarga di Desa Romang Tangaya, Kecamatan Manggala, Kota Makasar. Umar (2013) meneliti tentang pengetahuan dan kesiapsiagaan masyarakat menghadapi bencana banjir di Bolapapu Kecamatan Kulawi Sigi Sulawesi Tengah. Selain Makassar dan Umar, penelitian yang mengkaji kesiapsiagaan masyarakat dalam menghadapi bencana banjir antara lain penelitian yang dilakukan oleh Aji (2015), Mulyani (2014), Nurromansyah \& Setyono (2014) dan Waskitaningsih (2012). Sementara itu, beberapa penelitian terkait kesiapsiagaan warga sekolah terhadap bencana banjir antara lain penelitian dari Firmansyah (2014), Asror (2015), Triyani (2013). Akan tetapi tiga penelitian terakhir hanya fokus mengkaji kemampuan kesiapsiagaan komunitas sekolah pada jenjang SMA/SLTA/MA yang memiliki kecenderungan lebih siapsiaga secara psikologis dan usia jika dibandingkan dengan tingkat SMP/SLTP/MTs. Oleh sebab itu, penelitian ini memfokuskan kajian pada jenjang pendidikan tingkat SMP tepatnya di Madrasah Tsanawiyah Muhammadiyah Trucuk. Sehingga kajian ini akan menjadi pelengkap khazanah pengetahuan tentang upaya pengurangan risiko bencana banjir khususnya di tingkat atau jenjang pendidikan SMP/MTs. Oleh sebab itu, penelitian ini bertujuan untuk 1) Mengetahui tingkat pemahaman warga sekolah tentang bencana banjir, 2) Mengetahui tingkat kesadaran warga sekolah terhadap upaya pengurangan risiko bencana banjir dan 3) Mengetahui tingkat kesiapsiagaan warga sekolah dalam upaya pengurangan risiko bencana banjir. Sehingga melalui ke tiga indikator tersebut dapat diketahui upaya pengurangan risiko bencana banjir yang dilakukan di Madrasah Tsanawiyah Muhammadiyah Trucuk Kabupaten Klaten.

\section{METODE PENELITIAN}

Penelitian ini merupakan penelitian survei dengan pendekatan deskriptif. Metode survei digunakan untuk mendapatkan data dari tempat tertentu yang alamiah (bukan buatan), tetapi peneliti melakukan perlakuan dalam pengumpulan data, misalnya dengan instrumen, kuisoner, test, wawancara terstruktur (Sugiyono, 2011). Penelitian ini dimulai dengan penyusunan instrumen penelitian, pengumpulan data dan analisis data. Dalam pengumpulan data dilakukan dengan metode observasi, wawancara dan penyebaran kuisoner. Responden dalam penelitian ini merupakan guru dan siswa yang berada di sekolah Madrasah Tsanawiyah Muhammadiyah Trucuk. Instrumen yang digunakan dalam penelitian ini terdiri dari instrumen utama dan instrumen pendukung. Survei dilakukan terhadap 176 orang responden baik terdiri dari guru maupun siswa. Adapun teknik analisis data yang digunakan ialah teknik analisis statistik dengan bantuan SPSS. Sasaran yang ingin dicapai melalui pengumpulan dan analisis data yaitu data tentang: 1) tingkat pemahaman warga sekolah tentang bencana banjir, 2) tingkat kesadaran warga sekolah terhadap upaya pengurangan risiko bencana banjir dan 3) tingkat kesiapsiagaan warga sekolah dalam upaya pengurangan risiko bencana banjir. Melalui hasil analisis data terhadap tiga indikator tersebut maka diharapkan dapat diketahui bagaimana upaya pengurangan resiko bencana banjir di sekolah, khususnya di Madrasah Tsanawiyah Muhammadiyah Trucuk. Pelaksanaan penelitian secara sistematik dilakukan mulai dari tahap perencanaan, observasi awal, perizinan, pengumpulan data, analisis data, dan evaluasi. Penelitian ini dilaksanakan pada tanggal 3-6 November 2019 di Kabupaten Klaten khususnya di Kecamatan Trucuk dengan sasaran penelitian ini adalah guru dan siswa di Madrasah Tsanawiyah Muhammadiyah Trucuk. Adapun untuk lebih jelasnya, lokasi penelitian dapat dilihat pada peta lokasi penelitian sebagaimana ditunjukkan pada gambar 1. 


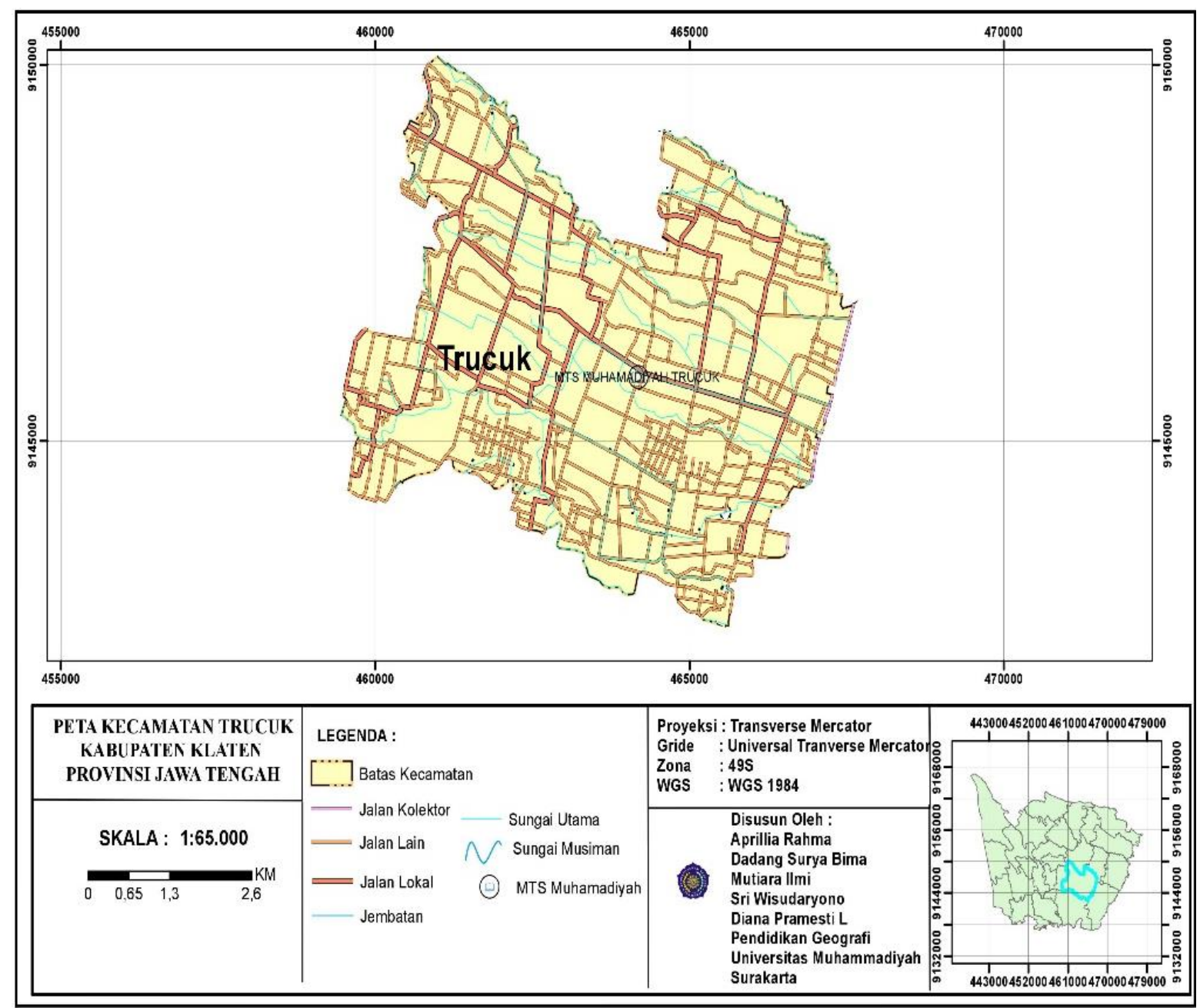

Gambar 1. Peta Kecamatan Trucuk

(Sumber: Peneliti, 2019)

\section{TEMUAN DAN PEMBAHASAN}

Pada hasil penelitian ini, dapat menjabarkan 3 pembahasan hasil berdasarkan variabel yang digunakan dalam penelitian yaitu: 1) tingkat pemahaman warga sekolah tentang bencana banjir, 2) tingkat kesadaran warga sekolah tentanng upaya pengurangan risiko bencana, dan 3) kesiapsiagaan warga sekolah dalam upaya pengurangan risiko bencana.

\section{Pemahaman warga sekolah terhadap bencana banjir}

Salah satu indikator awal untuk mengetahui bahwa seseorang dapat siapsiaga terhadap suatu bencana adalah pengetahuannya terhadap bencana tersebut, termasuk bencana banjir (Kharisma, 2009 dalam Purnamasari, 2013). Maka untuk dapat bersikap siapsiaga terhadap bencana banjir maka harus memiliki pengetahuan yang memadai tentang bencana banjir tersebut. Mulai dari pengetahuan apa yang dimaksud dengan banjir, bagaimana proses terjadinya, apa saja jenis-jenis banjir, bagaimana karakteristiknya, apakah termasuk dalam kategori bencana atau tidak, serta pertanyaan-pertanyaan lainnya yang harus berusaha dijawab dengan sebaik-baiknya. Sehingga dengan kemampuan menjawab berbagai pertanyaan seputar banjir tersebut, maka diketahui tingkat pemahaman seseorang terhadap bencana banjir itu sendiri. Adapun berdasarkan hasil survei yang telah dilakukan terhadap guru dan siswa di Madrasah Tsanawiyah Muhammadiyah Trucuk, maka diperoleh hasil tingkat pemahaman warga sekolah terhadap bencana banjir sebagaimana disajikan dalam bentuk diagram batang pada gambar 2 . 


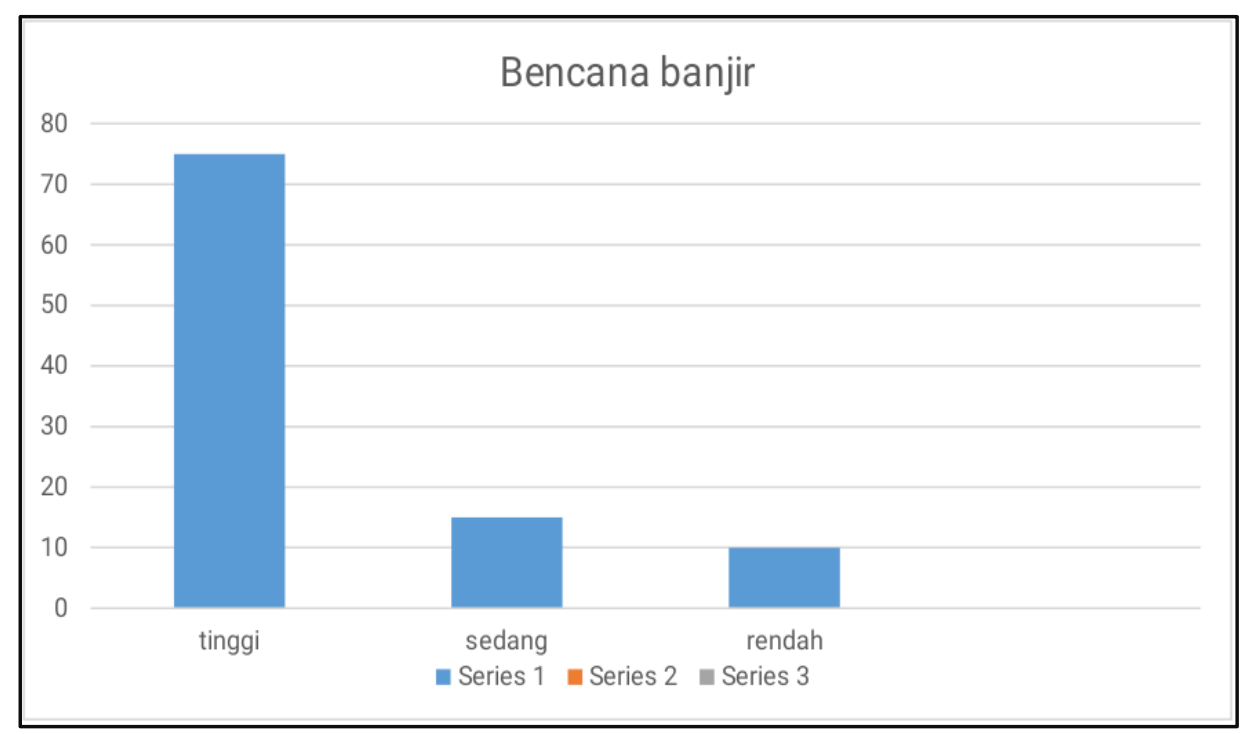

Gambar 2. Tingkat pemahaman warga sekolah terhadap bencana banjir

(Sumber: Hasil olahan data primer, 2019)

Berdasarkan gambar 2 di atas, dapat diketahui bahwa tingkat pemahaman warga sekolah terhadap bencana banjir di Madrasah Tsanawiyah Muhammadiyah Trucuk, termasuk dalam kategori tinggi dengan menempati angka 75\%. Dapat diartikan bahwa bencana banjir di Madrasah Tsanawiyah Muhammadiyah Trucuk sangat sering terjadi terutama pada saat musim penghujan, hampir sebagian besar wilayah di Trucuk terutama lingkungan Madrasah Tsanawiyah Muhammadiyah Trucuk mendapat ancaman yang tinggi dari bahaya bencana banjir.

2. Kesadaran warga sekolah terhadap upaya pengurangan risiko bencana banjir

Setelah memiliki pengatahuan atau pemahaman yang memadai menganai bencana banjir termasuk risiko yang mungkin terjadi, maka akan timbul sebuah kesadaran. Terutama kesadaran terhadap pentingnya upaya mengurangi risiko bencana banjir tersebut. Susanti, et al. (2014) menyatakan bahwa kesadaran merupakan faktor penting yang menggerakkan seseorang untuk siapsiaga dalam menghadapi bencana yang akan terjadi.

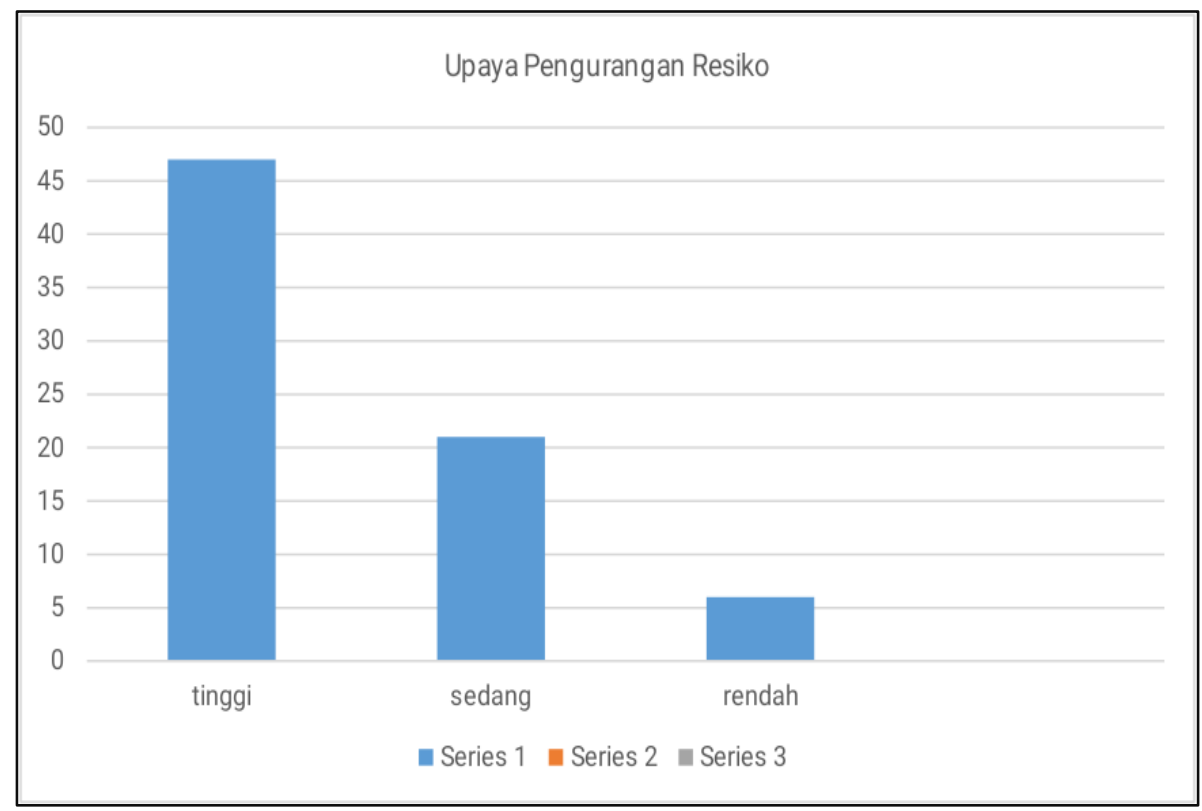

Gambar 3. Kesadaran tentang upaya pengurangan risiko bencana banjir

(Sumber: Hasil olahan data primer, 2019) 
Berdasarkan hasil analisis data terkait kesadaran warga sekolah dalam upaya penguranagan risiko bencana maka dapat disajikan sebagaimana pada gambar 3. Pada gambar tersebut data hasil analisis disajikan dalam bentuk diagram batang. Dari data tersebut dapat dilihat bahwa tingkat kesadaran warga sekolah dalam upaya pengurangan resiko bencana banjir di Madrasah Tsanawiyah Muhammadiyah Trucuk tergolong tinggi, yaitu mencapai 47\%. Dapat diartikan bahwa kesadaran warga sekolah terhadap ancaman bencana banjir di lingkungan Madrasah Tsanawiyah Muhammadiyah Trucuk dapat mengubah pola pikir mereka tentang pentingnya upaya pengurangan risiko bencana banjir sehingga diharapkan dapat mengurangi timbulnya jumlah korban yang tinggi.

3. Kesiapsiagaan warga sekolah dalam upaya pengurangan risiko bencana banjir

Kesiapsiagaan merupakan indikator ke tiga dalam upaya pengurangan risiko bencana. Semakin tinggi tingkat kesiapsiagaan seseorang terhadap bencana maka semakin tinggi pula kemampuannya mengurangi risiko bencana, termasuk bencana banjir. Berdasarkan hasil analisis data penelitian, maka dapat disajikan dalam bentuk diagram batang sebagaimana ditunjukkan pada gambar 4 .

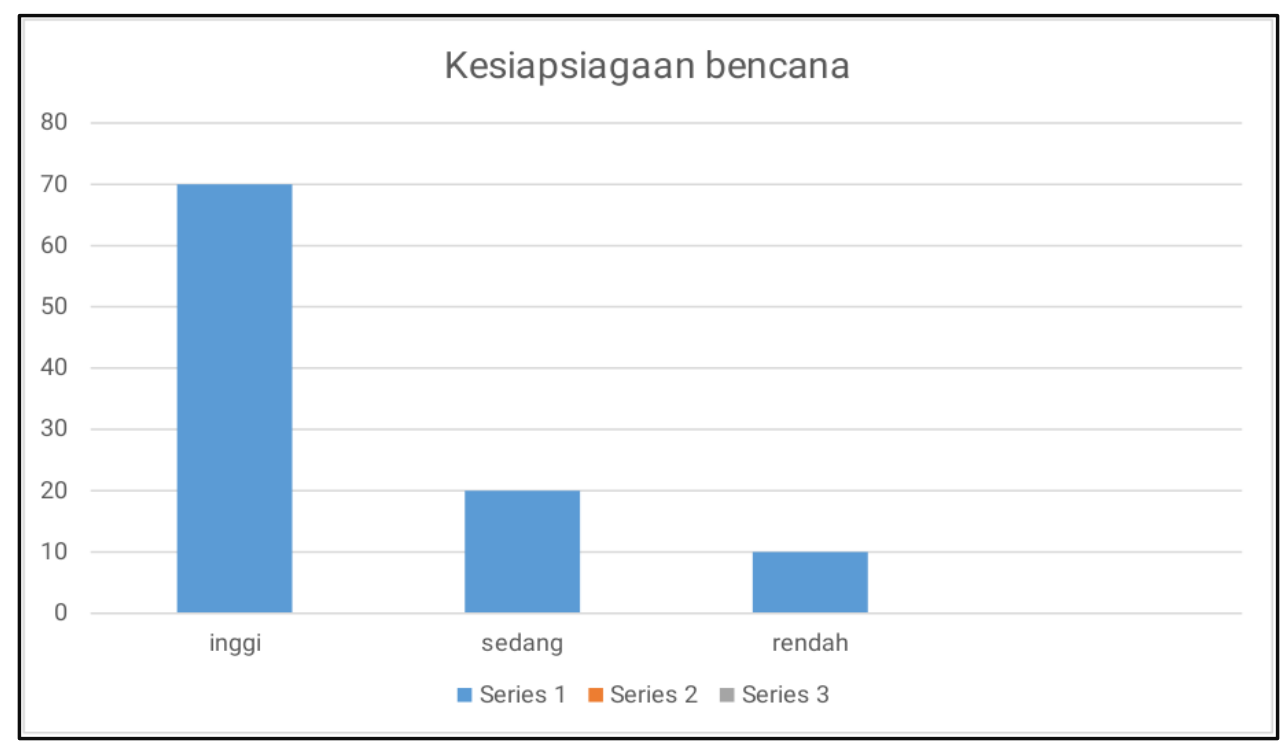

Gambar 4. Kesiapsiagaan warga sekolah terhadap bencana banjir (Sumber: Hasil olahan data primer, 2019)

Kesiapsiagaan bencana warga sekolah di Madrasah Tsanawiyah Muhammadiyah Trucuk terutama jika dilihat dari segi fasilitas keamanan tergolong tinggi yaitu dengan presentase $70 \%$. Dapat diartikan bahwa infrastruktur, pemahaman maupun kesadaran warga sekolah Madrasah Tsanawiyah Muhammadiyah Trucuk tentang bencana banjir dapat membantu menumbuhkan sikap kesiapsiagaan terhadap bencana, khususnya di lingkungan sekolah.

Adapun untuk sampai pada kesimpulan penelitian maka dilakukan serangkaian analisis data, yaitu dengan uji statistik, di mana dalam penelitian ini digunakan aplikasi SPSS guna mempermudah peneliti dalam mendapatkan hasil penelitian. Uji statistik yang digunakan yaitu uji asumsi klasik. Uji asumsi klasik berupa uji normalitas yaitu uji yang digunakan untuk mengetahui variabel yang akan dianalisis dalam penelitian ini berdistribusi normal atau tidak. Adapun berdasarkan hasil analisis data maka dapat dilihat pada tabel 1 sebagai berikut. 
Tabel 1. Hasil Uji Normalitas Tingkat Pengetahuan

One-Sample Kolmogorov-Smirnov Test

\begin{tabular}{|ll|r|}
\hline & & \multicolumn{1}{|c|}{$\begin{array}{c}\text { Unstandardized } \\
\text { Residual }\end{array}$} \\
\hline $\mathrm{N}$ & Mean & 176 \\
Normal Parameters ${ }^{\mathrm{a}, \mathrm{b}}$ & Std. Deviation &, 0000000 \\
& Absolute & 1,36323011 \\
& Positive &, 122 \\
Most Extreme Differences & Negative &, 118 \\
& &,- 122 \\
Kolmogorov-Smirnov Z & & 1,617 \\
Asymp. Sig. (2-tailed) &, 011 \\
\hline
\end{tabular}

Sumber : Hasil olahan data primer, 2019.

Berdasarkan tabel 1 hasil pengujian dari variabel penelitian dapat disimpulkan bahwa residu pada variabel yang di uji yaitu variabel tingkat pengetahuan berdistribusi normal karena memiliki nilai 0,011 yang lebih besar dari 0,05.

Tabel 2. Hasil Uji Pemahaman Warga Sekolah

One-Sample Kolmogorov-Smirnov Test

\begin{tabular}{|ll|r|}
\hline & & \multicolumn{1}{|c|}{$\begin{array}{c}\text { Unstandardized } \\
\text { Residual }\end{array}$} \\
\hline N & Mean & 176 \\
Normal Parametersa,b & Std. Deviation &, 0000000 \\
& Absolute & 1,51044591 \\
& Positive &, 156 \\
Most Extreme Differences & Negative &, 154 \\
& &,- 156 \\
Kolmogorov-Smirnov Z & & 2,068 \\
Asymp. Sig. (2-tailed) &, 000 \\
\hline
\end{tabular}

Sumber : Hasil olahan data primer, 2019.

Berdasarkan tabel 2 hasil pengujian dari variabel penelitian dapat disimpulkan bahwa residu pada variabel yang di uji yaitu pemahaman warga sekolah berdistribusi tidak normal karena memiliki nilai 0,000 yang lebih kecil dari 0,05 . 
Tabel 3. Hasil Uji Kesiapsiagaan Warga Sekolah

One-Sample Kolmogorov-Smirnov Test

\begin{tabular}{|c|c|c|}
\hline & & $\begin{array}{l}\text { Unstandardized } \\
\text { Residual }\end{array}$ \\
\hline $\mathrm{N}$ & & 176 \\
\hline Normal Parametersa,b & Mean & ,0000000 \\
\hline & Std. Deviation & 1,51044591 \\
\hline & Absolute & , 156 \\
\hline Most Extreme Differences & Positive & , 154 \\
\hline & Negative &,- 156 \\
\hline Kolmogorov-Smirnov Z & & 2,068 \\
\hline Asymp. Sig. (2-tailed) & & ,000 \\
\hline
\end{tabular}

Sumber : Hasil olahan data primer, 2019.

Berdasarkan tabel 3 hasil pengujian dari variabel penelitian dapat disimpulkan bahwa residu pada variabel yang di uji yaitu kesiapsiagaan warga sekolah berdistribusi tidak normal karena memiliki nilai 0,000 yang lebih kecil dari 0,05 .

Uji multikolinearitas dilakukan untuk mengetahui ada atau tidaknya korelasi yang tinggi antara variabel-variabel penelitian. Pengambilan keputusan yang digunakan pada uji ini oleh peneliti yang digunakan pada uji ini oleh peneliti ialah menggunakan nilai variance inflation factors (VIF), apabila nilai VIF, jika VIF < 10 maka tidak terjadi multikolinearitas Kemudian apabila VIF > 10 maka terjadi multikolinearitas antar variabel penelitian (Siswandari, 2015).

Hasil uji multikolinearitas pada variabel tingkat pengetahuan, pemahaman warga sekolah, dan kesiapsiagaan warga sekolah dalam penelitian ini di tunjukkan pada tabel berikut.

Tabel 4. Hasil Uji Multikolinearitas Tingkat Pengetahuan

\section{Coefficientsa}

\begin{tabular}{|c|c|c|c|c|c|c|c|}
\hline \multirow{2}{*}{ Model } & \multicolumn{2}{|c|}{$\begin{array}{c}\text { Unstandardized } \\
\text { Coefficients }\end{array}$} & $\begin{array}{c}\text { Standardized } \\
\text { Coefficients }\end{array}$ & \multirow{2}{*}{$\mathrm{t}$} & \multirow{2}{*}{ Sig. } & \multicolumn{2}{|c|}{ Collinearity Statistics } \\
\cline { 2 - 4 } & $\mathrm{B}$ & $\begin{array}{c}\text { Std. } \\
\text { Error }\end{array}$ & Beta & & & Tolerance & VIF \\
\hline $\begin{array}{c}\text { (Constant) } \\
\text { Tingkat } \\
\text { Pengetahuan }\end{array}$ &,- 105 & 1,567 & &,- 067 &, 947 & & \\
\hline
\end{tabular}

Sumber : Hasil olahan data primer, 2019.

Berdasarkan tabel 4, hasil pengujian dari variabel penelitian tersebut dapat disimpulkan bahwa nilai VIF Pada variabel yang di uji memiliki nilai 1,000 yang lebih kecil dari 10 sehingga tidak terjadi multikolinearitas antara tingkat pengetahuan dengan pemahaman warga sekolah serta kesiapsiagaan warga sekolah dalam upaya pengurangan resiko bencana. 
Tabel 5. Uji Multikolinearitas Pemahaman Warga Sekolah

Coefficients $^{\mathrm{a}}$

\begin{tabular}{|c|c|c|c|c|c|c|c|}
\hline \multirow{2}{*}{ Model } & \multicolumn{2}{|c|}{$\begin{array}{c}\text { Unstandardized } \\
\text { Coefficients }\end{array}$} & \multirow{2}{*}{$\begin{array}{c}\begin{array}{c}\text { Standardized } \\
\text { Coefficients }\end{array} \\
\text { Beta }\end{array}$} & \multirow{2}{*}{$\mathrm{t}$} & \multirow{2}{*}{ Sig. } & \multicolumn{2}{|c|}{ Collinearity Statistics } \\
\hline & $B$ & $\begin{array}{l}\text { Std. } \\
\text { Error }\end{array}$ & & & & Tolerance & VIF \\
\hline (Constant) & 3,091 &, 571 & & 5,416 &, 000 & & \\
\hline $\begin{array}{c}\text { Pemahaman } \\
\text { Warga }\end{array}$ &, 364 &, 152 & ,553 & 2,395 &, 032 & 1,000 & 1,000 \\
\hline
\end{tabular}

Sumber : Hasil olahan data primer, 2019.

Berdasarkan tabel 5 hasil pengujian dari variabel penelitian tersebut dapat disimpulkan bahwa nilai VIF pada variabel yang diuji memiliki nilai 1.000 yang lebih kecil dari 10 sehingga tidak terjadi multikolinearitas antara pemahaman warga sekolah dengan tingkat pengetahuan serta kesiapsiagaan warga sekolah dalam upaya pengurangan resiko bencana.

Tabel 6. Uji Multikolinearitas Kesiapsiagaan Warga Sekolah

Coefficients ${ }^{a}$

\begin{tabular}{|c|c|c|c|c|c|c|c|}
\hline \multirow{2}{*}{ Model } & \multicolumn{2}{|c|}{$\begin{array}{c}\text { Unstandardized } \\
\text { Coefficients }\end{array}$} & $\begin{array}{c}\text { Standardized } \\
\text { Coefficients }\end{array}$ & \multirow{2}{*}{$\mathrm{t}$} & \multirow{2}{*}{ Sig. } & \multicolumn{2}{|c|}{$\begin{array}{c}\text { Collinearity } \\
\text { Statistics }\end{array}$} \\
\cline { 2 - 4 } \cline { 7 - 9 } & $\mathrm{B}$ & Std. Error & Beta & & & Tolerance & VIF \\
\hline $\begin{array}{c}\text { Kesiapsiagaan } \\
\text { Warga }\end{array}$ & 3,071 & 1,087 & & 2,825 &, 014 & & \\
&, 142 &, 280 &, 139 &, 506 &, 621 & 1,000 & 1,000 \\
\hline
\end{tabular}

Sumber : Hasil olahan data primer, 2019.

Berdasarkan tabel 6 hasil pengujian dari variabel penelitian tersebut dapat disimpulkan bahwa nilai VIF pada variabel yang diuji memiliki nilai 1.000 yang lebih kecil dari 10 sehingga tidak terjadi multikolinearitas antara kesiapsiagaan warga sekolah dengan tingkat pengetahuan serta pemahaman warga sekolah dalam upaya pengurangan risiko bencana.

\section{SIMPULAN}

Berdasarkan hasil penelitian, maka dapat disimpulkan bahwa 1) tingkat pemahaman warga sekolah di Madrasah Tsanawiyah Muhammadiyah Trucuk tentang bencana banjir berada pada kategori tinggi (75\%), 2) tingkat kesadaran warga sekolah terhadap bencana banjir juga tinggi (47\%) dan 3) tingkat kesiapsiagaan warga sekolah di Madrasah Tsanawiyah Muhammadiyah Trucuk juga berada pada kategori tinggi (70\%). Dengan demikian maka dapat disimpulkan bahwa upaya warga sekolah dalam pengurangan risiko bencana banjir di Madrasah Tsanawiyah Muhammadiyah Trucuk Kabupaten Klaten rata-rata berada pada kategori tinggi. Adapun rencana tindak lanjut terhadap upaya pengurangan resiko bencana banjir bagi warga sekolah akan siap dan bersedia terus dilakukan jika regulasi dan mekanismenya jelas dan komprehensif. Selain itu juga kedepan diharapkan dapat dilakukan berbagai kegiatan yang dapat meningkatkan kesiapsiagaan bencana bagi warga sekolah. Terutama melalui pelatihan ekstrakurikuler dalam bidang kebencanaan. 


\section{DAFTAR PUSTAKA}

Aji, A. (2015). Kesiapsiagaan Masyarakat dalam Menghadapi Bencana Banjir Bandang di Kecamatan Welahan Kabupaten Jepara. Indonesian Journal of Conservation, 4(1).

Asror, L. N. (2015). Tingkat Kesiapsiagaan Siswa Terhadap Bencana banjir Di SMA Negeri 1 Tawangsari Kabupaten Sukoharjo (Doctoral dissertation, Unniversitas Muhammadiyah Surakarta).

Firmansyah, I. (2014). Hubungan Pengetahuan Dengan Perilaku Kesiapsiagaan Dalam Menghadapi Bencana Banjir dan Longsor Pada Remaja Usia 15-18 Tahun di SMA Al-Hasan Kemiri Kecamatan Panti Kabupaten Jember.

Makassar, T. (2011). Pengaruh penyuluhan tentang kesiapsiagaan bencana banjir terhadap pengetahuan dan sikap kepala keluarga di Desa Romang Tangaya Kelurahan Tamangapa Kecamatan Manggala Kota Makassar. Jurnal Program Pascasarjana Universitas Hasanuddin. Halaman 1-12.

Mulyani, D. (2014). Kesiapsiagaan Masyarakat Dalam Menghadapi Bencana Banjir Di Desa Ngombakan Kecamatan Polokarto Kabupaten Sukoharjo (Doctoral dissertation, Universitas Muhammadiyah Surakarta).

Nurromansyah, A. N., \& Setyono, J. S. (2014). Perubahan Kesiapsiagaan Masyarakat DAS Beringin Kota Semarang dalam Menghadapi Ancaman Banjir Bandang. Jurnal Wilayah dan Lingkungan, 2(3), 231-244.

Purnamasari, I. (2013). Pengaruh Simulasi Bencana Terhadap Kesiapsiagaan Pramuka Dalam Menghadapi Benacana Banjir di SMP Negeri 3 Mojolaban Kecamatan Mojolaban Kabupaten Sukoharjo. Naskah Publikasi. Fakultas Keguruan dan IImu Pendidikan, Universitas Muhammadiyah Surakarta.

Siswandari. (2015). Statistika Computer Based Cetakan. Surakarta: UNS Press.

Sugiyono. (2011). Metode Penelitian Kuantitatif, Kualitatif dan R\&D. Bandung: Afabeta.

Susanti, R., Sari, S. A., Milfayetty, S., \& Dirhamsyah, M. (2014). Hubungan Kebijakan, Sarana dan Prasarana dengan Kesiapsiagaan Komunitas Sekolah Siaga Bencana Banda Aceh. Jurnal IImu Kebencanaan: Program Pascasarjana Unsyiah, 1(1).

Triyani, Y. (2013). Kesiapsiagaan Sekolah Dalam Menghadapi Bencana Banjir Di SMP Islam Bakti 1 Kelurahan Joyotakan Kecamatan Serengan Kota Surakarta (Doctoral dissertation, Universitas Muhammadiyah Surakarta).

Umar, N. (2013). Pengetahuan dan Kesiapsiagaan Masyarakat Menghadapi Bencana Banjir di Bolapapu Kecamatan Kulawi Sigi Sulawesi Tengah. Jurnal Keperawatan Soedirman, 8(3): 105119.

Undang-Undang Republik Indonesia Nomor 24 Tahun 2007 tentang Penanggulangan Bencana.

Waskitaningsih, N. (2012). Kearifan lokal masyarakat sub-sistem drainase bringin dalam menghadapi banjir. Jurnal Pembangunan Wilayah \& Kota, 8(4): 383-391. 